\title{
Atividade antifúngica de extratos de Momordica charantia L. sobre Colletotrichum musae
}

\author{
CELOTO, M.I.B. ${ }^{1}$; PAPA, M.F.S. ${ }^{*}$; SACRAMENTO, L.V.S. ${ }^{2}$; CELOTO, F.J. ${ }^{1}$ \\ ${ }^{1}$ Faculdade de Engenharia, Departamento de Fitossanidade, Engenharia Rural e Solos, FE-UNESP, CEP 15385-

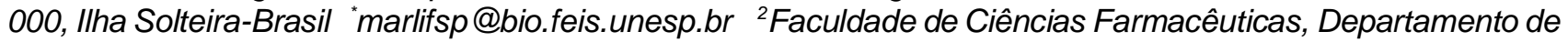 \\ Princípios Ativos Naturais e Toxicologia, FCF-UNESP, CEP 14810-290, Araraquara-Brasil
}

\begin{abstract}
RESUMO: Os objetivos do presente trabalho foram avaliar os efeitos de extratos de Momordica charantia sobre o crescimento micelial e a germinação de conídios de Colletotrichum musae, e a eficiência destes extratos no controle da antracnose, causada por $C$. musae, em bananas. Extratos aquoso e hidroetanólico, obtidos de folhas e ramos, na concentração de $50 \%$ em relação ao volume adicionado, em meio sólido, proporcionaram 71 e $65 \%$ de inibição do crescimento micelial, respectivamente, enquanto que em meio líquido, a inibição do crescimento micelial foi de $86 \mathrm{e}$ $81 \%$, respectivamente. Somente o extrato aquoso e o tiofanato metílico, nas concentrações de $50 \%$ e $1000 \mu \mathrm{g} \mathrm{mL}^{-1}$ respectivamente, proporcionaram 100\% de inibição da germinação de esporos de C. musae. Os extratos metanólico e aquoso inibiram em 80 e $70 \%$, respectivamente, o desenvolvimento das lesões em bananas, quando aplicados até dois dias antes da inoculação do fungo. Estes resultados foram semelhantes ao tratamento com tiofanato metílico, que inibiu $80 \%$ do desenvolvimento das lesões. Confirma-se a presença de substância antifúngica nos extratos de $M$. charantia e outros estudos devem ser realizados para viabilizar seu uso no controle da antracnose da banana.
\end{abstract}

Palavras-chave: Musa spp., melão-de-são-caetano, antracnose, extratos vegetais, controle alternativo

\begin{abstract}
Antifungal activity of Momordica charantia L. extracts against Colletotrichum musae. The aims of the present work were to evaluate the effects of Momordica charantia extracts on mycelial growth and conidial germination of Colletotrichum musae, as well as the efficiency of these extracts in controlling anthracnose caused by $C$. musae in bananas. Water and hydroethanol extracts were obtained from leaves and branches at $50 \%$ concentration relative to the added volume. In solid medium, extracts led to 71 and $65 \%$ mycelial growth inhibition, respectively, whereas in liquid medium the mycelial growth was inhibited at 86 and $81 \%$, respectively. Only water extract and thiophanate-methyl, at $50 \%$ and $1000 \mathrm{~g} \mathrm{~mL}^{-1}$, respectively, resulted in $100 \%$ inhibition of $C$. musae spore germination. Methanol and water extracts inhibited by 80 and $70 \%$, respectively, the development of lesions in bananas when applied until two days before fungal inoculation. These results were similar to those of the treatment with thiophanate-methyl, which inhibited $80 \%$ development of lesions. The presence of antifungal substance was confirmed in $M$. charantia extracts. Future studies must be performed to make its use viable for the control of anthracnose in bananas.
\end{abstract}

Key words: Musa spp., bitter melon, anthracnose, plant extracts, alternative control

\section{INTRODUÇÃO}

As doenças de pós-colheita da banana (Musa spp.) são de grande importância, principalmente para os frutos destinados à exportação, destacando-se a antracnose causada por Colletotrichum musae (Berk. \& Curtis) Arx. (Bastos \& Albuquerque, 2004; Cordeiro et al., 2005). As lesões de antracnose originam-se de duas formas distintas: lesões originadas de infecções que ocorrem em frutos verdes, permanecendo latentes até o amadurecimento; lesões oriundas de infecções ocorridas em pós-

Recebido para publicação em 05/12/2009

Aceito para publicação em 18/11/2010

Rev. Bras. PI. Med., Botucatu, v.13, n.3, p.337-341, 2011. 
colheita, decorrente de ferimentos na superfície dos frutos, resultando em lesões não latentes (Cordeiro et al., 2005). Esta doença diminui a vida de prateleira e a atração do consumidor pelo fruto, afetando assim, a qualidade e quantidade de banana disponível para exportação e consumo local (Khan et al., 2001; Anthony et al., 2004).

Para o controle da doença vêm sendo utilizados tratamentos químicos e práticas culturais, com a finalidade de reduzir a quantidade de inóculo no campo. Em pós-colheita, os fungicidas imazalil e tiabendazol estão registrados para o uso, por meio de imersão ou pulverização dos frutos e do engaço (Brasil, 2010), associado ao sistema de embalagem e transporte em condições de refrigeração (Cordeiro et al., 2005). Entretanto, a restrição ao uso destes produtos, devido a problemas de efeitos residuais, espectro de ação e resistência pelo patógeno, tem levado à procura de métodos alternativos de controle tais como, uso de biofungicidas, extratos de plantas e óleos vegetais (Khan et al., 2001; Bastos \& Albuquerque, 2004; Thangavelu et al., 2004; Peres et al., 2009), que minimizem o uso de fungicidas convencionais (Anthony et al., 2004; Sponholz et al., 2004; Silva et al., 2008).

Momordica charantia L. (Cucurbitaceae), conhecida popularmente como melão-de-sãocaetano, é considerada planta daninha e medicinal. $\mathrm{Na}$ medicina popular é utilizada no tratamento de coceiras, sarnas e impinge (Lorenzi \& Matos, 2002). Na medicina tradicional vem sendo estudada para o tratamento da diabete (Batran et al., 2006) e da Síndrome da Imunodeficiência Adquirida (AIDS) (Ng et al., 1992). Recentemente, começou a ser estudada no controle de doenças de plantas (Celoto et al., 2008) e nematoides (Batista et al., 1999).

Os objetivos do presente trabalho foram avaliar os efeitos de extratos de Momordica charantia sobre o crescimento micelial e a germinação de conídios de Colletotrichum musae, e a eficiência destes extratos no controle da antracnose, causada por C. musae, em bananas.

\section{MATERIAL E METODO}

O trabalho foi desenvolvido no Laboratório de Microbiologia e Fitopatologia, da Faculdade de Engenharia, da Universidade Estadual Paulista "Júlio de Mesquita Filho" - UNESP, em Ilha Solteira, SP, no período de janeiro a junho de 2005.

A partir de folhas e ramos secos de $M$. charantia, coletados na região de llha Solteira, SP, foram obtidos os extratos aquoso e hidroetanólico, como descrito por Celoto et al. (2008). Foi depositada exsicata do material de $M$. charantia no Herbário de Ilha Solteira/UNESP, sob o número de registro 7510. Os extratos metanólico e hidrometanólico foram obtidos no Laboratório de Química Orgânica do Instituto de Química, da Universidade Estadual Paulista, em Araraquara, SP, pelo processo de maceração das folhas e ramos, que permaneceram em contato com o solvente por sete dias. Após a extração, o solvente foi filtrado em papel pregueado, concentrado em rotaevaporador até a obtenção dos extratos secos. Os extratos foram mantidos em refrigerador a $10^{\circ} \mathrm{C}$.

A partir de frutos de bananeira, oriundos de supermercado do município de llha Solteira, SP, com sintomas de antracnose, foi realizado isolamento direto do fungo em meio de cultura Batata-DextroseÁgar (BDA). Pelo aspecto da colônia e dos esporos obtidos o fungo foi identificado como C. musae. As colônias obtidas foram preservadas em tubos de ensaio com solução salina (Castellani, 1939) e mantidas em refrigerador a $10^{\circ} \mathrm{C}$.

Foram realizados dois ensaios in vitro para avaliar o efeito dos extratos de $M$. charantia em diferentes concentrações, sobre o crescimento micelial e a germinação dos conídios de C. musae. Alíquotas dos extratos foram adicionadas aos meios BDA e Batata-Dextrose (BD) antes da autoclavagem e vertidos em placas de Petri e frascos de vidro (347 $\mathrm{mL}$ ) para as concentrações finais de 5, 15, 25 e 50\% dos extratos aquoso ou hidroetanólico e de 1, 10, 100 e $1000 \mu \mathrm{g} \mathrm{mL}^{-1}$ dos extratos metanólico e hidrometanólico. Foi utilizado o fungicida tiofanato metílico, do grupo químico dos benzimidazóis, como um tratamento padrão para comparação com os tratamentos dos extratos, uma vez que o mesmo é relatado como eficiente no controle de $C$. musae (Ventura \& Hinz, 2002). O tiofanato metílico foi incorporado aos meios BDA e BD, fundentes, nas concentrações de 1, 10, 100 e $1000 \mu \mathrm{g} \mathrm{mL}^{-1}$. No tratamento testemunha foi utilizado apenas meio BDA e BD sem adição de extrato ou fungicida. Cada placa de Petri e frasco de vidro receberam um e dois discos de $0,5 \mathrm{~cm}$ de diâmetro, retirados da borda de colônias do fungo, respectivamente. Em seguida, as placas foram incubadas em câmara de crescimento a $25^{\circ} \mathrm{C}$, sob fotoperíodo de $12 \mathrm{~h}$, e os frascos de vidro foram mantidos em temperatura ambiente de $25 \pm 3^{\circ} \mathrm{C}$, sob fotoperíodo de $12 \mathrm{~h}$ e agitação constante em agitador orbital (40 rpm). Após seis dias, mediu-se o diâmetro do crescimento micelial do fungo desenvolvido nas placas de Petri e o peso seco do micélio do fungo nos frascos de vidro.

Para o teste de germinação, foi preparada uma suspensão de conídios, com seis dias de idade, calibrada em $4 \times 10^{3}$ esporos $\mathrm{mL}^{-1}$. Em cada célula da placa de Elisa ("Enzime-linked immunosorbent assay"), foram colocadas $50 \mu \mathrm{L}$ de suspensão de esporos e $50 \mu \mathrm{L}$ de extrato ou fungicida, de modo a obter as concentrações desejadas. Essas placas

Rev. Bras. PI. Med., Botucatu, v.13, n.3, p.337-341, 2011. 
foram incubadas por 48 horas em câmara úmida a $25^{\circ} \mathrm{C}$. No tratamento testemunha, foi adicionada água destilada esterilizada. Em microscópio ótico realizouse a contagem de 100 esporos em cada célula, considerando-se como esporo germinado aqueles que apresentaram tubo germinativo igual ou maior que a largura.

O delineamento estatístico utilizado foi o inteiramente casualizado com quatro repetições, sendo cada parcela constituída por uma placa de Petri, um frasco de vidro ou duas células da placa de Elisa.

A partir dos resultados obtidos foram determinadas as percentagens de inibições do crescimento micelial (PIC) e da germinação de esporos (PIG) para cada tratamento, em relação ao tratamento testemunha, conforme Celoto et al. (2008). Em seguida, os dados foram submetidos à análise de variância pelo teste $\mathrm{F}$, comparando-se as médias pelo teste de Tukey a $5 \%$ de probabilidade, utilizando o software SAS (SAS Institute, 2002).

A concentração efetiva para inibição do crescimento micelial em $50 \%\left(E_{50}\right)$ e a dose letal para inibição de $50 \%$ da germinação dos esporos $\left(\mathrm{DL}_{50}\right)$ foram estimadas por meio de regressão linear.

No teste in vivo foram utilizados frutos de bananeira da variedade Missouri colhidos no estádio de maturação, com a casa ainda verde, na Fazenda de Ensino e Pesquisa da FE/UNESP, no município de Selvíria, MS. Os frutos foram lavados em solução de hipoclorito de sódio $0,5 \%(\mathrm{v} / \mathrm{v})$ e em água corrente. Para a inoculação, em cada fruto foi realizado ferimento superficial $(0,5 \mathrm{~cm}$ de diâmetro) e colocados disco de $0,5 \mathrm{~cm}$ de diâmetro de BDA mais crescimento fúngico, retirados de colônias do fungo. Foram avaliados seis tratamentos: 1) extrato aquoso sem diluição; 2) extrato hidroetanólico sem diluição; 3) extrato metanólico a $1000 \mu \mathrm{g} \mathrm{mL}^{-1}$; 4) extrato hidrometanólico a $1000 \mu \mathrm{g} \mathrm{mL}^{-1}$; 5) tiofanato metílico a $1000 \mu \mathrm{g} \mathrm{mL}-1$ e 6) testemunha adicional (sem aplicação). As aplicações foram feitas 1, 24, 48 e 72 horas antes da inoculação e 24 e 48 horas após a inoculação. Após as inoculações, os frutos foram acondicionados em câmara úmida por 48 horas e a seguir, mantidos em condições de laboratório $(25 \pm$ $\left.3^{\circ} \mathrm{C}\right)$, dispostos em prateleiras, inteiramente casualizados, por 11 dias, até a maturação. As avaliações foram efetuadas mediante ao desenvolvimento da antracnose por meio de medidas do diâmetro das lesões.

No ensaio in vivo os tratamentos foram arranjados em esquema fatorial, com cinco tratamentos e seis épocas de aplicação $(1,24,48$ e 72 horas antes da inoculação e 24 e 48 horas após a inoculação) e a testemunha adicional com quatro repetições, sendo cada repetição constituída por dois frutos de bananeira.

\section{RESULTADO E DISCUSSÃO}

De acordo com os resultados referentes ao efeito dos extratos de M.charantia na inibição da germinação de conídios e no crescimento micelial de C. musae (Tabela 1), observa-se que o extrato aquoso e o fungicida tiofanato metílico proporcionaram $100 \%$, de inibição da germinação dos conídios, diferindo significativamente dos demais extratos. $\mathrm{O}$ fungicida inibiu $100 \%$ do crescimento micelial do patógeno e o extrato aquoso $71 \%$. O extrato aquoso provavelmente apresentou menor efeito no crescimento micelial devido à autoclavagem do extrato. Celoto et al. (2008) observaram que extrato aquoso de $M$. charantia não autoclavado, inibiu 91,6\% do crescimento micelial de C. gloeosporioides a $20 \%$, e $61,4 \%$ quando foi submetido a autoclavagem.

O ajuste das equações de regressão foi significativo para as diferentes concentrações dos

TABELA 1. Médias das percentagens de inibição do crescimento micelial (PIC), em meios sólido e líquido e da germinação de esporos (PIG) de Colletotrichum musae por extratos de Momordica charantia e tiofanato metílico. Ilha Solteira, SP. 2005.

\begin{tabular}{lccc}
\hline \multirow{2}{*}{ Tratamento e dose } & \multicolumn{2}{c}{ PIC } & \multirow{2}{*}{ PIG } \\
& Meio Sólido & Meio Líquido & \\
\hline Extrato Aquoso $-50^{1}$ & $71 \mathrm{~b}^{\star}$ & $86 \mathrm{~b}^{\star}$ & $100 \mathrm{a}^{\star}$ \\
Extrato Hidroetanólico $-50^{1}$ & $65 \mathrm{c}$ & $81 \mathrm{c}$ & $0 \mathrm{~d}$ \\
Extrato Metanólico $-1000^{2}$ & $54 \mathrm{~d}$ & $55 \mathrm{~d}$ & $57 \mathrm{~b}$ \\
Extrato Hidrometanólico $-1000^{2}$ & $36 \mathrm{e}$ & $44 \mathrm{e}$ & $42 \mathrm{c}$ \\
Tiofanato Metílico $-1000^{2}$ & $100 \mathrm{a}$ & $97 \mathrm{a}$ & $100 \mathrm{a}$ \\
\hline CV $(\%)$ & 1,13 & 2,69 & 2,34 \\
\hline
\end{tabular}

\footnotetext{
${ }^{1}$ Valor da dose em \%; ${ }^{2}$ Valor da dose em $\mu \mathrm{g} \mathrm{mL}{ }^{-1}$; * Médias seguidas por letras distintas, nas colunas, diferem entre si
} (Tukey 5\%).

Rev. Bras. PI. Med., Botucatu, v.13, n.3, p.337-341, 2011. 
extratos de $M$. charantia, demonstrando o efeito linear das concentrações sobre a inibição do crescimento micelial e germinação de conídios de $C$. musae, ou seja, com o aumento da concentração dos extratos foi verificada maior inibição do crescimento micelial e da germinação de esporos (Tabela 2). Segundo Thangavelu et al. (2004), o grau de inibição in vitro está diretamente correlacionado com a concentração de extratos de plantas em BDA. Ao testarem extratos de Solanum torvum, em diferentes concentrações contra C. musae, os autores observaram inibição micelial completa quando utilizaram as maiores concentrações de extratos (25 e 50\%).

O fungicida tiofanato metílico inibiu completamente o crescimento micelial e a germinação de conídios de $C$. musae para todas as concentrações avaliadas (Tabela 2). Na classificação dos níveis de toxidez para fungos, proposta por Edgington et al. (1971), composto com $\mathrm{EC}_{50}<1 \mu \mathrm{g} \mathrm{mL}^{-1}$ possuem alta eficiência.
O extrato hidroetanólico apresentou valores de $\mathrm{EC}_{50}$ sobre o crescimento micelial, em meio sólido e líquido, abaixo da menor concentração testada (5\%), porém não apresentou efeito sobre a germinação dos conídios do patógeno (Tabela 2). Ao avaliar o extrato aquoso, verificaram-se valores de $\mathrm{EC}_{50}$ estimados em 23 e $13 \%$ sobre o crescimento micelial em meio sólido e líquido, respectivamente. $O$ valor da $\mathrm{DL}_{50}$ sobre a inibição de germinação de esporos de $C$. musae para o extrato aquoso foi estimado em $22 \%$, confirmando a presença de substâncias com atividade antifúngica (Tabela 2).

Os resultados referentes ao efeito dos extratos no controle da antracnose in vivo, estão apresentados na Tabela 3. Todos os tratamentos diferiram significativamente da testemunha, indicando a presença de substâncias antifúngicas nos extratos de $M$. charantia (Tabela 3). O tiofanato metílico apresentou maior efeito na redução da antracnose diferindo significativamente dos demais tratamentos.

TABELA 2. Equação de regressão linear (ERL), concentração efetiva para inibição de $50 \%$ do crescimento micelial $\left(\mathrm{EC}_{50}\right)$, em meio $\mathrm{BDA}$ e $\mathrm{BD}$, e dose letal para inibição de $50 \%$ da germinação dos conídios $\left(\mathrm{DL}_{50}\right)$ de Colletotrichum musae. Ilha Solteira, SP, 2005.

\begin{tabular}{|c|c|c|c|c|c|c|c|c|c|}
\hline \multirow[t]{3}{*}{ Tratamentos } & \multicolumn{6}{|c|}{ Crescimento micelial } & \multirow{2}{*}{\multicolumn{3}{|c|}{ G erminação de esporos }} \\
\hline & \multicolumn{3}{|l|}{ BDA } & \multicolumn{3}{|l|}{$\mathrm{BD}$} & & & \\
\hline & ERL & $R^{2}$ & $\mathrm{EC}_{50}$ & ERL & $\mathbf{R}^{2}$ & $\mathrm{EC}_{50}$ & ERL & $R^{2}$ & $\mathrm{DL}_{50}$ \\
\hline Aquoso & $y=1,09 x+25,07$ & $0,63^{*}$ & $23^{1}$ & $y=1,23 x+33,75$ & $0,71^{*}$ & $13^{1}$ & $y=2,13 x+2,17$ & $0,90^{\prime}$ & $22^{1}$ \\
\hline Hidrometanólico & $y=0,32 x+50,35$ & $0,83^{*}$ & $<5^{1}$ & $y=0,43 x+61,30$ & $0,90^{*}$ & $<5^{1}$ & ns & - & - \\
\hline Metanólico & $y=0,05 x+0,06$ & $0,99^{*}$ & $999^{2}$ & $y=0,05 x+3,39$ & $0,95^{*}$ & $932^{2}$ & $y=0,03 x+26,99$ & 0,69 & $767^{2}$ \\
\hline Hidrometanólico & $y=0,04 x-1,29$ & $0,99^{*}$ & $=1000:$ & $y=0,04 x+0,17$ & $0,99^{*}$ & $=1000^{\prime}$ & $y=0,03 x+17,25$ & $0,53^{\prime}$ & $=1000^{2}$ \\
\hline Tiofanato metilico & ns & - & _- & ns & - & - & ns & - & - \\
\hline
\end{tabular}

${ }^{1}$ Valores estimados a partir da equação de regressão linear, em \%; ${ }^{2}$ Valores estimados a partir da equação de regressão linear, em $\mu \mathrm{g} \mathrm{mL}^{-1}$; ns Não significativo ao nível de $5 \%$ de probabilidade; ${ }^{\star}$ Significativo ao nível de $1 \%$ de probabilidade.

TABELA3. Média dos diâmetros das lesões (cm), causadas por Colletotrichum musae em bananas da variedade Missouri tratadas com extratos aquoso, alcoólico, metanólico e hidrometanólico de Momordica charantia e com tiofanato metílico aos 11 dias após a instalação do experimento. Ilha Solteira, SP, 2005.

\begin{tabular}{|c|c|c|c|c|c|c|c|}
\hline \multirow{2}{*}{ Tratamentos $-\mu \mathrm{g} \mathrm{mL}^{-1}$} & \multicolumn{4}{|c|}{ Aplicação do ex trato antes da inoculação } & \multicolumn{2}{|c|}{$\begin{array}{l}\text { Aplicação do extrato } \\
\text { após a inoculação }\end{array}$} & \multirow{2}{*}{ Médias } \\
\hline & $72 \mathrm{~h}$ & $48 \mathrm{~h}$ & $24 \mathrm{~h}$ & $1 \mathrm{~h}$ & $24 \mathrm{~h}$ & $48 \mathrm{~h}$ & \\
\hline Aquoso $-100^{1}$ & $1,61 \mathrm{bA}{ }^{*}$ & $2,21 \mathrm{aA}$ & $0,88 \mathrm{cAB}$ & $0,85 \mathrm{cC}$ & $1,44 \mathrm{bB}$ & $1,41 \mathrm{bAB}$ & $1,40 \mathrm{C}$ \\
\hline Hidroetanólico - $100^{1}$ & $1,90 \mathrm{aA}$ & $1,94 \mathrm{aAB}$ & $1,18 \mathrm{bA}$ & $1,32 \mathrm{bB}$ & $1,30 \mathrm{bBC}$ & $1,24 \mathrm{bB}$ & $1,48 \mathrm{BC}$ \\
\hline Metanólico - $1000^{2}$ & $1,73 \mathrm{aA}$ & $1,34 \mathrm{aC}$ & $0,60 \mathrm{bB}$ & $0,65 \mathrm{bC}$ & $1,58 \mathrm{aAB}$ & $1,74 \mathrm{aA}$ & $1,27 \mathrm{D}$ \\
\hline Hidrometanólico - $1000^{2}$ & $1,57 \mathrm{bA}$ & $1,72 \mathrm{abB}$ & $0,52 \mathrm{cB}$ & $2,02 \mathrm{aA}$ & $1,94 a b A$ & $1,60 \mathrm{bAB}$ & $1,56 \mathrm{~B}$ \\
\hline Tiofanato Metílico - $1000^{2}$ & $0,75 \mathrm{bcB}$ & $0,62 \mathrm{cD}$ & $0,61 \mathrm{cB}$ & $0,62 \mathrm{cC}$ & $1,07 \mathrm{bC}$ & 1,77 aA & $0,90 \mathrm{E}$ \\
\hline Testemunha & - & - & - & - & - & - & $3,02 \mathrm{~A}$ \\
\hline
\end{tabular}

${ }^{1}$ Valor da dose em \%; ${ }^{2}$ Valor da dose em $\mu \mathrm{g} \mathrm{mL}^{-1}$; ${ }^{*}$ Médias seguidas de mesma letra, minúscula na linha e maiúscula na coluna, não diferem entre si pelo teste Tukey em nível de $5 \%$ de probabilidade. 
Ao avaliar os tratamentos observa-se que os melhores períodos de aplicação foram 1 e $24 \mathrm{~h}$ antes da inoculação do fungo, proporcionando os maiores efeitos na redução da antracnose, confirmando a ação protetora dos extratos e do tiofanato metílico. O tiofanato metílico inibiu mais de $80 \%$ do diâmetro das lesões, em relação à testemunha, quando aplicado 1 e $24 \mathrm{~h}$ antes da inoculação do fungo. $\mathrm{O}$ extrato metanólico proporcionou redução da antracnose igual ao fungicida, quando aplicado 1 e $24 \mathrm{~h}$ antes da inoculação do fungo, reduzindo 79 e 83\%, respectivamente, o diâmetro das lesões. Nestes mesmos intervalos de aplicação o extrato aquoso também apresentou redução significativa da antracnose, com mais de $70 \%$ do diâmetro das lesões, iguail ao tiofanato metílico e ao extrato metanólico.

A utilização dos extratos de $M$. charantia abre uma nova perspectiva de controle alternativo de fungos fitopatogênicos, especialmente a antracnose da banana, pois a presença de substâncias antifúngicas nos extratos desta planta foi confirmada no presente trabalho. Portanto, mais estudos necessitam ser realizados, como a determinação da(s) substância(s) antifúngica(s) presente(s), a demonstração da eficiência dos extratos no controle da doença em condições de campo, a adequação da produção de extrato e a formulação do extrato para uso em larga escala, as doses a serem utilizadas e a determinação da toxicologia dos extratos ao ambiente e ao homem.

\section{REFERÊNCIA}

ANTHONY, S. et al. Fungal pathogens associated with banana fruit in Siri Lanka, and their treatment with essential oils. Mycopathologia, v.157, p.91-7, 2004.

BASTOS, C.N.; ALBUQUERQUE, P.S.B. Efeito do óleo de Piper aduncum no controle em pós-colheita de Colletotrichum musae em banana. Fitopatologia Brasileira, v.29, n.5, p.255-7, 2004.

BATISTA, L.B. et al. Atividade ovicida e larvicida in vitro das plantas Spigelia anthelmia e Momordica charantia contra o nematódeo Ha-emonchus contortus. Ciência Animal, v.9, n.2, p.67-73, 1999.

BATRAN, S.A.E.S. et al. Some toxicological studies of Momordica charantia L. on albino rats in normal and alloxan diabetic rats. Journal of Ethnopharmacology, v.108, n.2, p.236-42, 2006.

BRASIL. Ministério da Agricultura, Pesca e Abastecimento. Sistema de Agrotóxicos Fitossanitários - AGROFIT. Disponível em: <http://extranet.agricultura.gov.br/agrofit_ cons/principal_agrofit_cons>. Acesso em: 10 nov. 2010. CASTELLANI, A. Viability of some pathogenic fungi in distilled water. Journal of Tropical Medice Hygiene, v.42, p.225, 1939.

CELOTO, M.I.B. et al. Atividade antifúngica de extratos de plantas a Colletotrichum gloeosporioides. Acta Scientiarum Agronomy, v.30, n.1, p.1-5, 2008.

CORDEIRO, Z.J.M.; MATOS, A.P.; KIMATI, H. Doenças da bananeira (Musa spp.). In: KIMATI, H. et al. (Eds.). Manual de fitopatologia: doenças das plantas cultivadas. 4.ed. São Paulo: Agronômica Ceres Ltda, 2005. p.99-117. EDGINGTON, L.V. et al. Fungitoxic spectrum of benzimidazoles compounds. Phytopathology, v.61, p.424, 1971.

KHAN, S.H. et al. Control of the anthracnose pathogen of banana (Colletotrichum musae) using antioxidants alone and in combination with thiabendazole or imazalil. Plant Pathology, v.50, p.601-8, 2001.

LORENZI, H.; MATOS, F.J.A. Plantas medicinais no Brasil: nativas e exóticas. Nova Odessa: Instituto Plantarum de Estudos da Flora, 2002. 544p.

NG, T.B. et al. Pro-teins with abortifacient, ribosome inactivating, immunomodulatory, antitumor and anti-AIDS activities from cucurbitaceae plants. General Pharmacology, v.23, p.579-90, 1992.

PERES, R. et al. Achillea millefolium - Asteraceae: estudo fitoquímico, espectrofotométrico e da atividade antifúngica (Colletotrichum musae). Revista Eletrônica de Farmácia, v.6, n.3, p.81-93, 2009.

SAS INSTITUTE. User's guide: statistic, version 9.1 . Cary: SAS Institute, 2002.

SILVA, M.B. et al. Tratamento térmico e prochloraz no controle da antracnose em pós-colheita de frutos de banana "Prata-Anã". Summa Phytopathologica, v.34, n.4, p.364-5, 2008.

SPONHOLZ, C. et al. Efeito do tratamento hidrotérmico e químico de frutos de banana "Prata" no controle da antracnose em pós-colheita. Fitopatologia Brasileira, v.29, p.480-5, 2004.

THANGAVELU, R. et al. Management of anthracnose disease of banana caused by Colletotrichum muse using plant extracts. The Journal of Horticultural Science and Biotechnology, v.79, n.4, p.664-8, 2004.

VENTURA, J.A.; HINZ, R.H. Controle das doenças da bananeira. In: ZAMBOLIM, L. et al. (Eds.). Controle de doenças de plantas fruteiras. Viçosa: UFV, 2002. v.1. p.838-938. 